\title{
Chapter 1 \\ Cosmopolitanism. The ideal of global justice, past and present
}

The idea that all humans form a morally relevant global community has a long history that continues to inspire and shape debates until today. This chapter introduces and explicates the notion of cosmopolitanism and will establish it as the first core element of a cosmopolitan ethos. It does so by discussing the idea of global citizenship and its normative content; and the major phases of its historical development to the present-with a particular focus on the Cynics, Stoics and the Enlightenment philosophy of Immanuel Kant. It provides a brief overview of the contemporary debate about global justice, some basic distinctions with regard to metrics and patterns of justice, and explains the relationship between thinking about global justice and about global ethics.

With this, the idea of world citizenship is introduced as the first and foundational normative element of my theory of cosmopolitan responsibility. Agents who understand themselves and others as citizens of the world will acknowledge the numerous morally relevant connections that link people across the globe. The scope of justice and the scope of one's moral concern will then no longer be limited by national borders; and global structural injustice-that links the advantages enjoyed by some with the disadvantages suffered by others-becomes a matter of urgent moral concern also for the privileged who, initially often unknowingly, benefit from it.

\section{Global citizenship}

The word "cosmopolitan" is of Greek origin and means "citizen of the world". It is a compound noun combining the words "cosmos" (world, order) and "polites" (citizen). The tension between these two components generates something akin to an oxymoron: after all, the notion of a citizen of the world seems to contradict itself. Citizenship is generally understood to be individual legal membership with a defined national, social and political community. The term as currently and conventionally used specifies a particular subgroup of humans who form a distinct-and by definition not an all-inclusive-community. In the classical Greek context, citizenship was linked to a specific polis, a city-state like Athens or Sparta. Later on, the nation-state became the primary unit specifying citizenship. Today, supranational institutions like the European Union have emerged 
that provide citizens of member states with an emerging, new form of supra-citizenship, although this is still dependent upon their prior national citizenship. What such developments demonstrate is that, whatever the current organising unit, the size, constitution and complexity of citizenship-conferring communities has varied over time and space, and continues to do so.

Citizenship refers to a special status that individuals possessing it enjoy, including a specific range of expected, required and permitted actions. Citizens are normally expected to participate in their community, to express their voice through, for example, voting on issues of communal importance. Furthermore, citizens, in exchange for following the laws governing their community, are entitled to certain advantages, such as the use of common goods or the privilege of traveling with a passport of the respective community. Such special status, defined by a specific set of expectations, obligations and entitlements, can only be conferred by a community that is institutionally organised in specific ways (Carens 2000). Due to this legal (or political) understanding of citizenship, citizenship in the cosmopolitan sense of being of the world may appear nonsensical.

However, a closer analysis of the word “cosmos” reveals an innovative and provocative idea that dispels the oxymoron. Unlike our contemporary understanding of "cosmos" as outer space (all that lies beyond our planet world as such), "cosmos" in the classical Greek sense had a very different connotation: it referred to the world as an already structured and organised harmonious whole. Cosmos signified for the Greeks the universal order governed by logos, and was the opposite of "chaos," the unstructured, formless and lawless void -in other words, the term had a meaning quite opposite to the one we currently attach to it. The assumption of such a meaningful and harmonious cosmic order, which is governed by natural (or divine) eternal laws, moderates the oxymoron in the word "cosmopolitan". It points to the possibility of perceiving individuals as members in a structure that expands beyond the polis or nation. Here, citizenship is understood as an anthropological or a psychological ${ }^{11}$ phenomenon that is largely independent of actual political or legal arrangements. The presumed contradiction fades away under this assumption and makes room for an admittedly optimistic ideal of coherence, and for allegiance to a community that transcends local groups. In this sense, humans as humans can be understood to

11 My distinction between a legal and a psychological understanding of citizenship is based upon the distinction between different dimensions of citizenship made by Carens. He suggests that there is a legal dimension of citizenship, referring to the legal status of an individual, a political dimension, regarding the individual's participation in collective decision making processes, but also a psychological dimension, that is constituted through psychological attachment (Carens 2000, 161-176). 
form a community for which all contingent discriminatory characteristics like nationality, religion, culture, class, ethnicity, sex, gender or sexual preference, etc. are irrelevant for community membership purposes.

The cosmopolitan claim of a single, normatively relevant community of all humans endorses the normative anthropological claim that, in spite of all factual and circumstantial differences between individuals, all living human beings are equally entitled to membership in this overarching human community, which includes certain rights and entitlements, but also brings with it certain duties and obligations.

\section{Moral cosmopolitanism as egalitarian universalism}

Cosmopolitanism, the idea of "world-citizenship," is grounded in the fundamental idea that all human beings are jointly members of one global order, which is based on the widely shared normative assumption of the equal moral worth of all. Cosmopolitanism thus expresses a normative stance that gives rise to a moral project in several domains, most notably the political, cultural and moral. In its different forms, it (1) addresses a set of questions about living together, (2) shares a diagnosis, and (3) tends to agree on a set of central claims and commitments.

(1) The assumption of the existence of a single overarching human community that justifies regarding all individuals as "citizens" (at least metaphorically) suggests that there are certain expectations, requirements and entitlements connected to this status. Indeed, cosmopolitanism's central question is how should human beings coexist? How should we live together ${ }^{12}$ More concretely, this question can be split into several sub-questions: Which normative rules should govern human action in order to coexist well on planet Earth? ${ }^{13}$ Which rights and entitlements do human individuals have as citizens of the world? And which obligations and duties do they have to meet, towards one another and also towards non-human animals and the environment?

(2) Asking these questions follows from the particular diagnosis of what I have called in the introduction the de facto "circumstances of cosmopolitanism". They consist of three elements. First, all humans, whatever the differences be-

12 The adequate way of living together will also have implications for dealing with non-human animals and the environment. In any case, Nagel correctly and pointedly states that "we really do not know how to live together" (Nagel 1991, 5).

13 "The ethical life belongs to human beings, living together in ever larger groups, and working out their shared lives with one another." (Kitcher 2012, 2) For this, see also below, chapter two. 
tween individuals, are strikingly similar with regard to trans-temporally, transculturally, and inter-individually stable features. Human beings generally all have a roughly similar body, basic needs and interests, they also have standardly a capacity to have experiences, feel emotions and to reason, even if the concrete ways in which these capacities are used and experienced may differ to some degree between individuals, groups and cultures. Humans are able to interact and to communicate with one another, establishing relations that can bridge existing differences, including differences of language and culture. The obvious differences in, say, languages, fashion, parenting styles or burial rites thus must not obscure the striking similiarities between humans accross time and regions: all are needy creatures, all relate to and depend from others (at least during some periods of their lives), all can standardly govern their behaviour through employing reasoning and deliberation, and all have an interest in being well. ${ }^{14}$ These features ground the idea of a community of humans.

Second, we live in an increasingly interconnected world in which actions have both direct and indirect impact on the lives of many others. I would argue that this was already true at the very beginning of human history: rare in the historical record are individuals or communities that were permanently self-sufficient. New human groupings and settlements originated from the interactions and movements of older ones, and even when groups seek to define themselves as self-sufficient (or even hostile to other groups), those others are by definition the counterpart of such self-understandings. Once population levels increase in any area, meeting and interacting between groups becomes inevitable: it is and remains nearly impossible to abstain permanently from interaction with others. Nor is it possible not to have an impact on the lives of others, or not to be influenced by their actions (Appiah 2007). Such interaction and mutual impact is not impeded by the demarcation of groups, nor, in more recent times, by national boundaries. Today, global trade and climate change are but two particularly striking examples of the far-reaching entanglement of all human lives. The products we buy have often been produced in far away places, and so a long causal chain of interactions connects individual consumer decisions with the working conditions of manufacturers, sometimes very far away. Individual actions that generate $\mathrm{CO}_{2}$-emissions directly contribute to processes like global warming: flying anywhere in the world, from Albania to Zambia, materially adds to the amount of greenhouse gases in the atmosphere that influence weather phenomena elsewhere. And even those living in remote areas of the planet, e.g. the Maldives, are not merely heavily affected by the activities of others in

14 Cf. Appiah (2007), Ganten et al. (2008), Heilinger (2010, part IV), Nussbaum (2011a). 
far away places that contribute to changing weather patterns and rising sea levels; entire islands are at risk of disappearing completely and forever as a result.

The significance of these two elements of the diagnosis of the de facto circumstances of cosmopolitanism-the possibility and inevitable reality of human interconnectedness-is heightened by a third observation: the striking contrast between the living conditions of humans in different places on the planet, which are defined by an almost unimaginable scale of inequality with many people not even having sufficient means to live a minimally decent life, due to poverty, exploitation, environmental degradation, etc. ${ }^{15}$ The existing inequalities indicate a problem that can appear in an absolute and a relative form: Absolute deprivation is always morally problematic, because the basic needs of people are not met. Relative inequality might turn out to be less worrisome from a moral perspective, if those worse off are still reasonably well off and are able to live a decent life. Relative inequality, however, becomes particularly problematic, if the worse off are denied the opportunity to live a decent life all the while the relatively better off not only have access to the conditions of a decent life, but enjoy massive amounts of privileges and advantages, that are generated and upheld, at least partly, even at the expense of the worse off. This is the morally outrageous situation of our current world, constituting the third element of the descriptive diagnosis of the circumstances of cosmopolitanism.

(3) On these grounds a distinctively cosmopolitan position will take a normative stance. The particular normative commitment of cosmopolitans is that of egalitarian universalism taken seriously, with real world outcomes as the yardstick. The cosmopolitan perspective can be used in two senses: it can normatively evaluate and assess a given state of affairs, and it can be guide and demand particular forms of action and reform ${ }^{16}$-always based on the grounds of the equal moral standing of all.

The fundamental claim about equal moral status of each individual does not -in my view-stand in need for a specific justification beyond the widely shared description of circumstances of cosmopolitanism. ${ }^{17}$ The onus of proof lies, rath-

15 Extreme inequalities also occur within nations, raising problems similar to the ones discussed here. Cf. Milanovic (2011).

16 Beitz has distinguished cosmopolitanism as a "perspective" or "point of view" seeking to "encompass the whole world" on the one hand, and cosmopolitanism as a "substantive moral and political doctrine" on the other (Beitz 2005, 15).

17 However, such justifications of equal moral standing of humans are possible and standardly opt for one of three possibilities: shared needs, interests, or capacities, like reason, are seen as constitutive of equal value, external fixation of equal value by a divine entity or a natural law, or collective self-attribution of equal value through the community of communicating agents. Gen- 
er, on the side of those denying the fundamentally equal moral standing of all humans: those who might claim that some persons (women, people of colour, children, homosexuals or atheists, for example) do not have the same basic moral weight as others do, must provide arguments to defend the moral relevance of distinctions made on the grounds of gender, sexual preference, skin colour, age or religion. In the last few generations, many such distinctions have come rightfully under attack, some have already fallen. While the political realities in many parts of the world currently indicate challenges to such progress, even attack past achievements and institute regressive change, I assume that, based on the fundamentally self-evident insight into the moral equality of all, genuine progress will remain possible. ${ }^{18}$

Cosmopolitanism in any case argues that the fundamental claim about the moral equality of all has to be taken seriously. And because cosmopolitanism stresses this prima facie uncontroversial assumption, it becomes controversial, thus calling for further reflection. Three central normative elements can be identified within the cosmopolitan commitment to the equal moral standing of all: normative individualism, egalitarianism/impartiality, and universal scope. ${ }^{19}$

First, each and every human individual, as such, is a basic unit of moral concern (Pogge 1992, 48). No additional conditions beyond humanness are necessary to qualify a human individual as fully morally relevant. ${ }^{20}$ Notably, it is impermissible to make any exceptions and to exclude some from the moral concern because of their ethnicity, religion, nationality, family membership, sex, gender,

erally, the equal moral worth of all has become a foundational conviction in contemporary moral philosophy, cf. e.g. Dworkin (1977, 180-183) or Nagel (1991, 14). Note, however, that equal moral standing and the demand to treat all as moral equals does not imply that everyone has to be treated equally. Treating different people differently-e.g., by locking up the bank robber, while being friendly to one's cousin-may even be morally required in order to fully respect the fundamentally equal moral standing of everyone.

18 For a critical discussion of the claim that all persons have equal moral worth, cf. the papers collected in Steinhoff (2015) and Steinhoff (2013).

19 Cf. Pogge (2007, 316), Brown and Held (2010, 1-2), Pogge (1992, 48-49). The principles of normative individualism and egalitarian universalism can be found in many modern moral theories. Implicitly or explicitly, they are fundamental for Hobbes, Locke, Kant, and for utilitarian and contractarian theories.

20 The question whether the exclusive focus on human beings-and the corresponding neglect of animals and other rational or sentient beings-is problematic because in itself arbitrary (the objection of "speciesism") will not be discussed here. Equally, I will not address the challenge that some human beings like newborn children or severely mentally impaired people are not in a full sense persons, if personhood is based on the condition of rationality. I will simply talk about human beings and interactions between human beings, while being aware of some unanswered questions in the background. 
sexual preference, culture, etc. Furthermore, only human individuals are such units of concern. 'Races,' religious groups, nations, families, etc., have no independent moral standing, as normative collectivists might argue. For normative individualists, collectives matter morally only insofar as the individuals that are constitutive of the group matter.

Second, each of the individuals is to be seen as an equally important basic unit of moral concern. Not only are all human beings relevant, but they are equally relevant. Kings and beggars, criminals and saints, friends and strangers are indistinguishable in their fundamental moral relevance. They all have equal moral weight. Correspondingly, everyone's interests, needs, claims, well-being etc., are fundamentally of equal moral importance. The default weighing of the interests, etc., of different people is hence one that can be characterised as impartial. All deviations from such impartial consideration stand in need of particular justification. ${ }^{21}$

Third, the scope of cosmopolitanism is unrestricted and maximally inclusive. It is universal in two senses: no matter when and where an individual lives or who she or he is, she or he matters equally; and he or she also matters equally for everyone. The first sense stresses what Pogge has called the "all-inclusiveness" of moral cosmopolitanism, the second its "generality" (Pogge 2007): cosmopolitanism fundamentally asks every individual to expand his or her concern to every other individual.

It is clear that a cosmopolitan theory and practice will face many challenges, both theoretical and practical. If it is to become a defensible, widely accepted and policy-relevant view, one will have to spell out how exactly the cosmopolitan community distributes entitlements, permissions and obligations, and what would be the appropriate institutional arrangements to secure the core demands of cosmopolitanism. With the intention of making progress in this regard, the chapters in this book will take up important challenges and seek to advance the understanding of the complex notions of equality, responsibility, impartiality, rights and their practical implications. But first I want to focus further on the development of the cosmopolitan ideal in the history of ideas, since knowing the history of a concept may also help to understand its current use more accurately.

21 Unlike Pogge (1992), Pogge (2007) avoids the notion of "equality” when determining the central normative commitments of cosmopolitanism. To prevent the impression that cosmopolitanism endorses an egalitarian view about distributive justice, he talks of "impartiality" which better captures the idea that all individuals matter equally. I discuss both notions separately in chapters two and five below. 


\section{The evolution of cosmopolitanism}

The following section presents some important phases in the evolution of the idea that humans as citizens of the world form a morally relevant community. ${ }^{22}$ I will look at the origins and at the cosmopolitan "agenda setting" in ancient Greece and will present the unfolding of this ideal during the Enlightenment period, notably in Kant's seminal writings, before concluding with some brief thoughts about cosmopolitanism in the 19th and 20th century. It should become clear that the contemporary discussion of the content and form of cosmopolitan thinking owes much to its historical predecessors. What has mostly changed over time is that cosmopolitan ideals have become more and more applicable to an increasingly globalised-and thus factually cosmopolitan-reality.

\subsection{Cosmopolitanism in ancient Greek philosophy}

The explicit discussion of the notion of cosmopolitanism starts in the Greek Cynic and Stoic tradition at around 350 BCE. Yet, the idea that all human beings constitute a joint community is most probably even older and not restricted to the Western tradition of thought. The Egyptian pharaoh Akhenaten (around 1300 BCE) may already be seen as an early proponent of universalistic monotheism. He accepted that he had the same duties towards all human beings, regardless of their 'race' or nationality (Harris 1927). The Chinese philosopher Mozi (around $400 \mathrm{BCE}$ ) also endorsed an idea of impartiality on the basis of a principle of "universal love" (cf. Caney 2005b, 4). A similar idea of universal obligation towards all appears in the Hebrew bible, and both Homer and Herodotus endorsed claims that call for an overcoming of narrow conceptions of (polis-) patriotism (Harris 1927). However, the origin of an elaborated idea of world-citizenship can be found "in the earlier classical period of Greek thought" (Harris 1927, 2; Nussbaum 1997b).

Explicit discussion of cosmopolitanism appears to have begun with the controversial Diogenes of Sinope (400/390 - 328/323), one of the prominent figures of Cynicism. A skeptic of the culture of the Greek polis, he has been pointedly described as "a cross between a satirical comedian and a homeless performance artist” (Warburton 2013). He rejected all possessions and lived as a pauper in order to express his disdain for material wealth. Seneca and others report that

22 This section is particularly indebted to work by Nussbaum (1997b). It also contains revised material published earlier (Heilinger 2015). 
Diogenes had lived in a tub (Seneca, Ep., 90.14). Because of his "dog-like" lifestyle as a beggar without possessions, expressing without shame the different needs and impulses of his body in public, following like a dog the steps of Antisthenes whom he deeply admired (Diogenes Laërtius, VI.6, 18, 21), and because of his praise for the virtues of dogs, people called Diogenes himself a dog (Greek: kyon). Diogenes accepted this label as a title of honour and his teachings became known as Cynicism (Müller 1976, Ottmann 2001, 260, 276-288). ${ }^{23}$ It is reported that Diogenes disagreed with Plato about the adequate interpretation of Socrates' teachings: Plato was in Diogenes' eye too theoretical a philosopher, in contrast to Socrates, who had the right attitude towards the priority of practice. However, Diogenes agreed with both Socrates and Plato in certain respects: like both of them, he questioned the widely accepted ethical exclusivism which privileged the in-group of one's polis over all other humans.

The core elements of the emerging cynical philosophical school were the self-sufficiency of the wantless individual (autarchy), the need for open expression of thoughts (parrhesia or shameless speech) and-here one finds the first reported actual use of the word "cosmopolitan"-a universal conception of human community transcending city or state boundaries. Once, when asked where he came from, Diogenes is said to have answered: "I am a citizen of the world." 24 This claim to be a member of a universal community was perceived as a serious provocation of the established views because Diogenes implicitly rejected with this statement a definition of his own status and ancestry within the narrower terms of state or city affiliation that mattered so much to his fellow citizens. His self-description as cosmo-polites situates him in a larger community of all human beings-and in doing so places him outside of the narrowly confined borders of the Greek polis. Contradicting the standard self-perception of a citizen in a Greek polis in a way that must have appeared insulting to many, Diogenes drew a parallel between shared citizenship in a polis in the conventional understanding of his contemporaries on the one hand, and the mutual relationship of all human beings as cosmopolitans on the other. Such an expanded idea of shared citizenship implied that hospitality and fraternal affection were owed to all human beings, and not only to one's fellow citizens in a particular polis.

23 Diogenes Laërtius and Plutarch report further anecdotes about Diogenes, among them Diogenes going at plain daylight with a lamp to the Athenian marketplace and searching for an (honest) human being (an image later taken up by Nietzsche when presenting his Zarathustra). Diogenes is further said to have mocked Alexander the Great when the king promised to grant him a favour, whatever it may be: "Stand out of my sunlight!"

24 Cf. Diogenes Laërtius (VI.63); a saying, however, that Cicero also attributed to Socrates in Tusculanae Disputationes (Cicero, Tusc. Disp., V.37, 108). 
This early understanding of cosmopolitanism has two features that greatly influenced later uses of the concept. First, it seeks to empower the individual, insofar as one is freed from parochial allegiances to any narrower community such as the Greek polis-state. This was of particular importance to Diogenes since, in his time, the social structures of the polis had begun to decay and become increasingly fragile. Such individual self-assurance, expressed as independence from narrow-mindedness and crumbling communities, highlights the autarchy of each individual in a meaningful universal order. Second, this self-understanding of an empowered individual is embedded in the specific social concept of a universal community that is constituted by the relations between all individuals. It is this larger community within which humans stand in a relation of equality to one another, and in which mutual allegiances are owed.

The story continues with Diogenes teaching his Cynic thoughts to Crates of Thebes who influenced, together with Diogenes, Zeno of Citium, the founder of the school of Stoicism, which prevailed into Roman times. Zeno argued prominently for a universal "city under one law" 25 which specifies the claim of Diogenes to be a citizen of the world: the single law that all have to follow is conceived of as a natural law, existing independently of all agreements in particular cities or states. Here is how Plutarch presents Zeno's view:

The much admired Republic of Zeno is aimed at this one main point, that our household arrangements should not be based on cities or parishes, each one marked out by its own legal system, but we should regard all men as our fellow-citizens and local residents, and there should be one way of life and order, like that of a herd grazing together and nurtured by a common law. Zeno wrote this, picturing as it were a dream or image of a philosopher's well-regulated society. (Long and Sedley 1987, 429) ${ }^{26}$

Zeno's utopia hence went beyond the fraternal relations ${ }^{27}$ argued for by Diogenes. The universal natural law ultimately demands a universal political order to which all human beings submit.

Another Stoic, Hierocles, addressed a challenge implicit in any demand for a universal law and universal allegiances among all human beings as human be-

25 Even if the word "city" designates obviously not the entire world, the direction of Zeno's argument is clear. The notion of "law" is not to be understood in a modern sense. What Zeno refers to is again a meaningful structure governed by the "logos".

26 More philosophical sources about Stoic political philosophy can be found in Long and Sedley (1987, 429-437).

27 And, of course, one must not oversee that several groups of people-among them women and slaves-were not always fully acknowledged as equals even in accounts defending a universal and egalitarian expansion of concern. 
ings, which will also be discussed later in this book: How to deal with the particular and special relationships towards those nearer and dearer to us? If all human beings are equally important morally, then special treatment of my fellow citizens in local communities becomes problematic: Do we truly have to treat all human beings alike? How about the special concern I may foster for my parents and children, my friends, etc., as opposed to a general benevolence towards all human beings? Hierocles, living in the first and second century BCE, employed a metaphor-also later used by Cicero in his De Officiis (I.50 sqq.)-to make his point: we should understand our allegiances to other human beings as a series of "concentric circles," with ourselves being at the centre and the other human beings grouped around us in ever larger circles. The first circle around oneself would be the immediate family, then the extended family, next friends, neighbours, fellow polis-inhabitants until ultimately the largest circle would comprise all human beings. The challenge and the task of human beings as moral agents would then be to "draw the circles somehow toward the centre," so that the larger circle collapses with the next smaller circle.

Here is a long quote from Stobaeus, the compiler of extracts from Greek authors who worked in the early 5th century, illustrating in detail how Hierocles understood these concentric circles:

Each one of us is as it were entirely encompassed by many circles, some smaller, others larger, the latter enclosing the former on the basis of their different and unequal dispositions relative to each other. The first and closest circle is the one which a person has drawn as though around a centre, his own mind. [...] Next, the second one further removed from the centre but enclosing the first circle [...]. The third one has in it uncles and aunts, grandparents, nephews, nieces, and cousins. The next circle includes the other relatives, and this is followed by the circle of local residents, then the circle of fellow-tribesmen, next that of fellow-citizens, and then in the same way the circle of people from neighbouring towns, and the circle of fellow-countrymen. The outermost and largest circle, which encompasses all the rest, is that of the whole human race. Once these have all been surveyed, it is the task of a well-tempered man, in his proper treatment of each group, to draw the circles together somehow towards the centre, and to keep zealously transferring those from the enclosing circles into the enclosed ones [...]. The right point will be reached if, through our own initiative, we reduce the distance of the relationship with each person [...]. But we should do more, in the terms of address we use, calling cousins brothers, and uncles and aunts, fathers and mothers [...]. For this mode of address would be no slight mark of our affection for them all, and it would also stimulate and intensify the indicated contraction of the circles. (Long 1987, 349-350)

These cosmopolitan ideas about expanding the circles of concern and contracting the circles of proximity were taken up and refined more and more by the rich and diverse Roman Stoic tradition with proponents like Cicero, Seneca and Mar- 
cus Aurelius (Nussbaum 1994, ch. 9-12). ${ }^{28}$ In general, three main elements of Stoic cosmopolitan thinking appear to have evolved out of Diogenes' original claim..$^{29}$ First, the foundational starting point is the assumed similar human capacity for reason that is constitutive for the assumed universal community of all human beings. Reason is conceived of as the divine faculty that allows us to make moral choices, and this faculty is shared by all human beings as human beings. Nussbaum explains: "Male or female, slave or free, king or peasant, all are alike of boundless moral value, and the dignity of reason is worthy of respect wherever it is found. This reason, the Stoics held, makes us fellow citizens" (Nussbaum 1997b, 7).

A second important Stoic claim is the dual belonging of human beings to both a local and a global community both of which entail different kinds of moral obligations and rights. Starting from the assumption that it is purely by chance, by brute luck, that we are born into a given nation or particular community, it becomes necessary not to overrate this accidental and morally arbitrary fact. The Stoics do not deny our particular obligations in concrete surroundings; they do, however, deny that these obligations provide an excuse for not taking into account the appropriate concern owed to any other individual who happens not to be a compatriot or family member. As Nussbaum has it, again referring to the underlying shared capacity of reason, "We should recognize humanity wherever it occurs, and give its fundamental ingredients, reason and moral capacity, our first allegiance and respect” (Nussbaum 1997b, 7).

The third central claim is the Stoic stipulation of elements of a fundamental natural law that, if followed, would allow human beings to live in a universal harmony with one another and the world. Here, Stoic thought relies on metaphysical assumptions about divine entities to provide a justification for their claims about the existence of such a universal natural law. Yet, the assumption of a natural law-even on specifically religious grounds-does not lead Stoic thought to claim a single, true religion. Neither does Stoicism call for a single world state. As Nussbaum writes, the Stoics argue "that a style of political life that recognises the moral/rational community as fundamental promises a more reasonable style of political deliberation and problem solving, even when our institutions are still based on national divisions" (Nussbaum 1997b, 8, my italics). The Stoic claim hence allows for stepwise improvements or gradual developments towards more realisation of and compliance with the natural law, with-

28 This metaphor has a lasting impact until today (cf. e.g. Singer 1981, 120, Kitcher 2011, 215). 29 Here I follow a reading of these authors along the lines of Kantian ideas, similar to Brown and Held (2010, 4-5) and on the basis of Nussbaum (1997b). Kant's stance on cosmopolitanism will be explained below. 
out any totalitarian impulse to enforce these laws immediately. The Stoics' suggestions are certainly pertinent when thinking about how to organise the co-existence of all humans in the world. ${ }^{30}$

Based on these early ideas about cosmopolitanism, it is possible to identify three important challenges that are also much discussed in the contemporary debate about cosmopolitanism. First, we need an understanding of the anthropological underpinnings of any universalistic moral account: focussing predominantly or exclusively on reason (as done frequently in the Stoic and the Enlightenment tradition) might be too narrow and fail to capture the many relevant dimensions of human lives. The anthropological basis of cosmopolitan thinking has to be extended beyond reason, given that there is a bewildering plurality of possible properties that justify the special normative status of all human beings. ${ }^{31}$ Second, the double membership of human beings in both a local and a global community, diagnosed already by the Stoics, calls either for some kind of moderation of strong universal obligations or for some kind of holistic unification of universal and particular obligations, in order to avoid obvious contradictions between the differing claims from the two realms. It will be necessary to "embed" universalism: the challenge then consists in defining precisely how to deal with this factual plural membership in more than one community. Third, the Stoics started from the metaphysically demanding assumption of a fixed, eternal natural law that has currently lost much of its appeal. At best, we can-through anthropological considerations-identify certain core elements of human lives or conditions of human flourishing that justify legitimate moral claims or claims of justice, but these will be insufficient for stipulating or justifying any specific and determinate "natural law". ${ }^{32}$ The third challenge then consists in overcoming and replacing the idea of a natural law (and the assumption

30 It is interesting to see the central role Stoicism assigns to individual agency under cosmopolitan "law" in contrast to institutional arrangements. Choosing between an individual and an institutional understanding of cosmopolitanism will become an important challenge in contemporary cosmopolitan thinking.

31 Beside reason, it could be, e.g., the status of personhood, sentience, certain preferences or interests, will, needs, desires, an idea of human well-being, or capacities like the possibility to agree, to communicate, etc. I do not engage in a detailed discussion of how to justify the moral status of all humans in this book, but only stipulate that human beings should be understood as having both a needy, physical side that makes persons stand in need of other persons on the one hand, and an active side of-possibly rational, reasoned, moral, autonomous-agency on the other, where both sides are closely engaged with one another. Cf. e.g. Nussbaum (2011a), Anderson (1999, 317), and the contributions in Mackenzie and Stoljar (2000).

32 However, the "new natural law theorists" assume it is possible to justify at least a fundamental natural law (Finnis 1980). 
of a possible universal harmony) with another approach that allows one to make justified normative claims about obligations in the global domain.

Cosmopolitan thinking evolved further during late Antiquity and the Middle Ages, and Stoic cosmopolitanism continued influencing Christian thinkers like Paul, Augustine, Thomas Aquinas and Martin Luther. ${ }^{33}$ Particularly striking and consequently influential is the statement of universalism and a single human community by Paul: "There is neither Jew nor Gentile, neither slave nor free, nor is there male and female, for you are all one in Christ Jesus" (Gal 3, 28). Religious differences are-on this account-as irrelevant to this community, as are social or gender differences.

Particularly influential for the development of cosmopolitan thought were, according to Brown and Held, "the works associated with the School of Salamanca and the cosmopolitan theories generated by the Neo-Thomist thinkers of Bartolome de las Casas, Francisco de Vitoria, and Francisco Suarez" (Brown and Held 2010, 10). These thinkers developed the theory of a natural right and a natural law further-yet on ever stronger religious foundations. Its particular religious grounding, however, makes this tradition dubious to many today. The most forceful expression of cosmopolitanism in the history of philosophy appeared when the assumption of universal law was liberated from its specific religious underpinnings due to the religious scepticism of the Enlightenment period, notably in the work of Immanuel Kant.

\subsection{The Enlightenment expansion of cosmopolitan thought}

The Enlightenment period, with its optimistic belief in the possibilities for improving the human lot, developed the cosmopolitan idea into an elaborate and forceful normative view that had direct and indirect practical implications. As such, it has continued to inspire thinkers and practitioners to this day. Numerous Enlightenment philosophers embraced the idea of a morally significant joint membership of all humans in a single community-among them, most prominently, Hugo Grotius, John Locke, Voltaire, Thomas Paine, Adam Smith, Marquis de Condorcet and Thomas Jefferson (Forman-Barzilei 2009; Schlereth 1977). Cosmopolitanism was an integral element in the broader set of Enlightenment ideas that were in the air by that time, as it provided an ideal and a direction to guide the generally optimistic belief in progress and step-by-step change

33 Obviously, my account is limited in its focus on the tradition of Western philosophy; cf. Delanty (2014). 
in human lives towards perfection. Ultimately, the American Declaration of Independence, the French Revolution and the Declaration des Droits de l'Homme et $d u$ Citoyen, as well as the Haitian revolution and independence ${ }^{34}$ were born out of this cosmopolitan Enlightenment spirit, which insited upon the freedom of the individual, the equality of all and an overarching relationship between human beings. However, to some degree and in spite of their universal ambition, these all expressed a "cosmopolitanism within borders" (Wild and Heilinger 2013) in which the fundamentally egalitarian universalism was taken seriously only at the level of an individual country. An important pioneer of the extension of cosmopolitan reasoning beyond the state was Kant. ${ }^{35}$

Kant is the paradigmatic philosophical representative of the entire Enlightenment period. It was he who inspired ever more cosmopolitan thinking and, as Brown and Held rightly claim, "all [...] cosmopolitan themes are influenced, directly or indirectly, by Kant's moral and political philosophy" (Brown and Held 2010, 9).

Kant obviously wrote in a very different context than the Stoics. By the 18th century, people had become able to travel around the entire globe (although, perhaps interestingly, Kant himself did not), the actual economic interactions between peoples had increased significantly, and colonialism-with people forcefully entering countries and oppressing and exploiting others-had begun to be subjected to moral scrutiny. During the Enlightenment period, political thinking took into account these changed circumstances. Kant was sensitive to these developments and, in his influential work Perpetual Peace, he described an emerging global community in the following way:

The peoples of the earth have thus entered in varying degrees into a universal community, and it has developed to the point where a violation of laws in one part of the world is felt everywhere. The idea of a cosmopolitan law is therefore not fantastic and overstrained; it is

34 Although often neglected in listing the important progressive and egalitarian historic events in the spirit of Enlightenment, the Haitian revolution and subsequent declaration of independence from colonial France in 1804 merit special attention when studying egalitarian and cosmopolitan thinking. After all, the successful insurrection of self-liberated slaves was the only one that ultimately led to the founding of a state, firmly committed to the revolutionary ideals of egalitarianism, in which both former rulers and ruled, white and non-white people, ruled together. Only the Haitian revolution realised the universalism of human rights fully by overthrowing slavery, thus radicalising the notion of natural human rights by exposing the unsolved and persisting tensions and contradictions in American independence and the French declaration. Cf. the seminal James (2001 (1938)) and, more recently, Fick (2007), Knight (2000) and Bhambra (2015). 35 Kant's contribution and its historical context is analysed in Cheneval (2002). 
a necessary complement to the unwritten code of political and international law, transforming it into a universal law of humanity. (Kant AA 8: 360; ed. Reiss 107) ${ }^{36}$

In Perpetual Peace, Kant developed nothing less than a "theory of politics" (Gerhardt 1995) that takes into account the need for lawful interaction beyond the spheres of influence of the individual nation states.

The stipulation of a "cosmopolitan law," which would be added to the already existing forms of public law-constitutional and international-is the major theoretical innovation suggested by Kant in his treatise on Perpetual Peace. It is true that Kant is mostly known for his contribution to international law. His writings about a "league of nations" had a tangible impact which ultimately inspired and influenced the shaping of institutions like the actual League of Nations (1920) and the United Nations (1945). While such global political bodies do, of course, give rise to issues that will also be discussed under the label of political or legal cosmopolitanism (and hence figure as integral parts of the contemporary debate about cosmopolitanism), Kant used the term "cosmopolitan law" distinctively to designate a particular form of interaction, which is different from what is regulated by the other forms of law.

In cosmopolitan law, Kant stipulates, "individuals and states, coexisting in an external relationship of mutual influences, may be regarded as citizens of a universal state of mankind (ius cosmopoliticum)" (AA 8: 349; ed. Reiss 98-99). This universal state of mankind is the larger framework within which cosmopolitan law determines the dealings of individuals and states. It is based on understanding individuals as "citizens of the world" and not as citizens of a particular state with a particular nationality. The focus of ius cosmopoliticum is neither on the relationships between states (international law), nor on the relationship of citizens to "their own" states (constitutional law) but on the "status of individuals in their dealings with states of which they are not citizens" (Kleingeld 1998, 72).

In the scholarly literature about Kant's ius cosmopoliticum this somewhat unusual addition of a third sphere of law has been widely accepted (cf. Kleingeld 1998, Williams 2007). For instance, Kleingeld argues that "despite problems with how he works it out, Kant's idea of reserving theoretical space for a third level of public law in addition to constitutional and international law is sound" and "can be developed into a position that is relevant to contemporary issues" (Kleingeld 1998, 73).

36 I quote from Kant's Perpetual Peace in indicating the volume and pages from the German Akademieausgabe, but also the page of the English edition by Reiss (1991). 
To do full justice both to the depths of Kant's argument, and to recent scholarly debate about it, is not possible here for reasons of space. Such a discussion would also require extensive expertise in the field of law that I do not possess. Given the scope of this historical sketch, I will instead focus on the core of his cosmopolitan law as an important element in the history of cosmopolitan thinking.

In the third "Definitivartikel" of Perpetual Peace-preceded by the six "Präliminarartikel" describing immediate measures to be undertaken in order to progress towards perpetual peace, and by two more "definitive articles" stipulating what would be necessary for a lasting foundation of perpetual peace-Kant spells out the core of cosmopolitan law: the right to hospitality. Kant writes: "Cosmopolitan right shall be limited to conditions of universal hospitality" (8: 357; ed. Reiss 105). Now, this claim of hospitality seems rather modest, since it comprises only "the right of a stranger not to be treated with hostility when he arrives on someone else's territory" (8: 358; ed. Reiss 105). The right to hospitality does not even include, then, a right to be treated with friendliness nor as a welcome guest or visitor on someone else's territory. Rather, it only includes a right to come to the borders of another state and to contact other people and states in other parts of the world (cf. Gerhardt 1995, 105, Kleingeld 1998, 75).

However, this right, Kant explains, may only be denied "if this can be done without causing his death" (8: 358; ed. Reiss 105-106). The German word "Untergang," employed by Kant, is open to interpretation. "Death" is but one of its possible translations. Literally the terms is closest to "sinking" in English, but it is arguably employed more commonly to mean "ruin," "doom" or "demise" of a person. This may also consist of a person being tortured, oppressed etc.and does not necessarily have to involve one's certain death. On this wider understanding of "Untergang," it is possible to appreciate the wider implications of the right to hospitality. It implies a right to political asylum, as well as a right to be admitted into a foreign country if the chances of decent survival in the country of origin are low because of political insecurity, food shortages or natural disasters.

One may wonder why Kant did not explicitly mention these important and rather obvious implications of cosmopolitan law. But his quite modest demand for a right to hospitality can be explained from the specific circumstances Kant had in mind when formulating the cosmopolitan law. He was less concerned with the particular challenges of our time-e.g., refugees fleeing wars, natural disasters or extremely dire economic conditions. Instead, he focused more on the devastatingly intrusive and brutal practices of European colonialism. Here, 
the cosmopolitan law as stipulated by Kant develops its full impact: colonialism stands in clear violation of cosmopolitan law. ${ }^{37}$

Kleingeld convincingly sums up Kant's understanding of "universal hospitality". To him, it means "that states and individuals have the right to attempt to establish relations with other states and their citizens, but not a right to enter foreign territory. States have the right to refuse visitors, but not violently, and not if it leads to their destruction. This implies an obligation to refrain from imperialist intrusions and to provide safe haven for refugees" (Kleingeld 1998, 72).

To fully appreciate Kant's contribution to cosmopolitan thinking, it is important to be aware of the specific justification Kant offers for his cosmopolitan law. One might think that Kant employed here the basic assumptions of his moral reasoning, which sees every human being as a member of a kingdom of free rational beings and an end in her- or himself. This is the prominent foundation underlying Kant's Critique of Practical Reason and the Metaphysics of Morals. Yet, the justification he gives in the political context of Perpetual Peace is a different one.

Following again Kleingeld's concise reconstruction of the argument (Kleingeld 1998, 77-79, Kleingeld 2012), Kant's justification for cosmopolitan law is based on a right to communal possession of the earth's surface (cf. 8: 358; ed. Reiss 106), ${ }^{38}$ i.e., the idea that land is originally possessed by all before any initial acquisition of property, which would consequently prevent others from taking what now belongs to specific individuals. This understanding of the acquisition of individual property is similar to the acquisition of land by a nation, whose territory consequently cannot be claimed rightfully by foreigners arriving later. "But all parts of the earth [...] continue to be thought of as parts of the whole to which everyone had an original right. This [...] implies that all nations stand in a community of possible physical interaction" (Kleingeld 1998, 78). The possible physical interaction on the earth's surface, to which originally all humans have a right, seems to be the justification of cosmopolitan law that Kant offers in his political writings. Yet, this remains an incomplete and somewhat unsatisfactory argument, for it is not fully clear how the assumption of the original community of the land, which has been changed into rightfully ac-

37 Generally, Kant's relationship to colonialism was complex and shifted over time (cf. Ypi and Flikschuh 2014).

38 Recently, Risse, standing in a long tradition ranging from Grotius to Kant, has suggested such "common ownership of the earth" as a basis for claims and obligations in the context of global justice (Risse 2012). 
quired land, can lead, together with the sheer possibility of interaction, to the cosmopolitan right to hospitality.

The difficulties with Kant's justification probably explain why several scholars have suggested an alternative justification, which would have been available to Kant based on his general moral philosophy. In his contribution on the occasion of the 200th anniversary of the publication of Perpetual Peace, Habermas briefly points towards an argument for cosmopolitan law based on the fundamental theory of human autonomy and dignity (Habermas 1995, 303-304). Similarly, Nussbaum endorses such a reading of Kant's argument for cosmopolitan law (Nussbaum 1997b, 12) and Kleingeld follows Habermas when she writes that "the innate human right to freedom is all one needs to back up the principle of hospitality. For this right implies precisely the two aspects central to Kant's understanding of the hospitality principle: that prospective visitors have no right to intrude into the sphere of freedom of others against their will, and that neither states nor individuals have the right to refuse visitors when this would lead to the annihilation of their freedom (their destruction)" (Kleingeld 1998, 79).

On both grounds-the actual one offered in Perpetual Peace and the hypothesised one that later emerged from readings of his normative understanding of humans as rational beings-Kant's idea to augment constitutional and international law with cosmopolitan law is an important step in the evolution of cosmopolitan thinking. It may actually be best understood as the beginning of the transition from accounts based on natural rights, domestic law and international law, to historically novel modern accounts of individual rights in the context of institutions, such as nations, of which the respective individuals are not a part. While earlier forms of cosmopolitan thinking were spelled out in the form of equal moral standing within a given community (even if it was a global moral community), Kant's innovative suggestion paves the way for institutionalised rights that individuals have as moral subjects vis-à-vis institutional agents like states. He refines cosmopolitan thinking significantly by taking into account the realities of actual states as well as their interests in sovereignty. This formulation has also had a lasting impact on contemporary debates on human rights and international justice.

To conclude this brief discussion of Kant's idea of cosmopolitan law within his Perpetual Peace, I want to point to an ambiguity in Kant's writings that has influenced cosmopolitan reasoning ever since, which is his refusal to endorse the idea of a single international state. Kant's argument that a global governmental body with coercive powers would not be desirable for the implicit danger that it may turn into despotism was most notably expanded upon by Rawls. He writes: "I follow Kant's lead in Perpetual Peace (1795) in thinking that a world govern- 
ment [...] would either be a global despotism or else would rule over a fragile empire torn by frequent civil strife as various regions and peoples tried to gain their political freedom and autonomy" (Rawls 1999a, 36). Yet, Kant's take on this matter is-in spite of this reference-more ambiguous. This becomes particularly obvious in the paragraph immediately preceding the third definitive article, which spells out the cosmopolitan law. Kant writes:

\begin{abstract}
There is only one rational way in which states coexisting with other states can emerge from the lawless condition of pure warfare. Just like individual men, they must renounce their savage and lawless freedom, adapt themselves to public coercive laws, and thus form an international state (civitas gentium), which would necessarily continue to grow until it embraced all the peoples of the earth. But since this is not the will of the nations, according to their present conception of international right (so that they reject in hypothesi what is true in thesi), the positive idea of a world republic cannot be realised. If all is not to be lost, this can at best find a negative substitute in the shape of an enduring and gradually expanding federation likely to prevent war. (8: 357; ed. Reiss 105)
\end{abstract}

It is hence the empirical assumption that states will be unwilling to give up their interpretation of state sovereignty and international law, an interpretation that speaks, in Kant's view, against the idea of an international state (civitas gentium). Things have changed over the past 200 years, and the development of the League of Nations and the United Nations, as imperfect as they were and remain, have altered the international political landscape significantly. Many states are now actually willing to give up some degree of their sovereignty in order to gain a greater good, as is particularly obvious with the current European Union experiment (as beleaguered as it may be presently). One could also follow Kant's cosmopolitan reasoning with regard to the demand for an international, institutionalised body with at least some, although not unconditional, power. ${ }^{39}$

Kant's arguments have hence further developed the idea of cosmopolitanism and made it available and relevant even today. His distinctive focus on the cosmopolitan law provides a lasting inspiration for and influence upon contemporary cosmopolitans, even though, after Kant, the debates about cosmopolitanism have evolved further and gained more complexity.

39 Others have suggested that Kant may be a "false friend" in his rejecting a world government. After all, Kant favours a world republic over a league of nations and his argument for a league of sovereign states seems strategic, cf. Gerhardt (1995, 103-104), Kleingeld (1998, 83, fn. 19). 


\subsection{Economic and political cosmopolitanism}

During the 19th and 20th century, the moral and political forms of cosmopolitanism were further developed. Given the rapid developments in industrialisation, production and economic exchange, the dominating strain of cosmopolitanism during the time centred on economic relations and challenges. ${ }^{40}$ Communist thinkers Karl Marx and Friedrich Engels prominently endorsed cosmopolitanism in their writings, yet with a dual valence (Renton 2002, Henning 2006). On the one hand, they were sharply critical of cosmopolitanism, which they saw as an integral part of the ideology of capitalism. As a capitalist doctrine, cosmopolitanism was understood by such thinkers to have an inherent tendency to expand beyond borders in order to generate more capital and to access ever new markets. Free trade beyond borders can be labelled an economic version of cosmopolitanism since it claims the existence of a single, global market community of all human beings (cf. Nida-Rümelin 2006). According to Marx and Engels, however, such free trade allows the bourgeois class to exploit the whole world, while benefitting only that class and pauperising all others. On the other hand, Marx and Engels themselves suggest a transnational (in other words cosmopolitan) union of the proletariat of all countries to counter the capitalist version of economic cosmopolitanism. The exploitation suffered by the proletarians everywhere inspires a common interest to overcome the class-divided society. The call "Workers of the world, unite!" is meant to establish a cosmopolitan union of proletarians simply on grounds of their shared misery. Ultimately, revolution will follow from such a union, or so Marx and Engels argue. The result of this revolution, in turn, is supposed to be a class-less society which can be understood as "a form of cosmopolitanism of its own" (Kleingeld 2013, 9), because its scope will be truly global and not end at any national border. ${ }^{41}$

The effects of Enlightenment enthusiasm about cosmopolitanism also extended beyond the economic sphere. As already mentioned above, in the political domain, many of the ideas endorsed by Kant in his Perpetual Peace inspired political reasoning and action. The establishment of the League of Nations in 1920 and, following World War II, of the United Nations in 1945, stand firmly in the Enlightenment tradition. More recent developments like the installation of the International Criminal Court in 2002, also can be understood as steps

40 This section builds on Kleingeld (2013).

41 Smith, von Hayek and Friedman also defend economic cosmopolitanism as free global trade and open markets; cf. e.g. Forman-Barzilei (2009). 
that were already imagined much earlier as necessary contributions to securing peace among the nations.

Furthermore, the codification, refinement and implementation of Human Rights Law in the 20th century are serious attempts to determine precisely the fundamental rights and entitlements that individuals have "simply in virtue of their humanity" (Tasioulas 2012). Important steps after the Universal Declaration from 1948 were the two Covenants from 1976 (the International Covenant on Civil and Political Rights, ICCPR, and the International Covenant on Economic, Social and Cultural Rights, ICESCR) and later steps undertaken to transform the claims of the declaration into actually binding international law.

Cosmopolitan ideas about the limited importance and moral irrelevance of nationality have been practically realised by international aid agencies like The International Red Cross and Red Crescent Movement, Oxfam, Partners in Health, Médicins du Monde, Médicins sans Frontières, and many others. These organisations aim to help people in need, such as victims of wars, famines, and natural catastrophes, wherever possible. In so doing, they do not restrict the scope of their attention to any specific region or group of individuals (cf. Forsythe and Rieffer-Flanagan 2007).

So far, a sequence of three main steps in the history of cosmopolitan thinking and practice have been identified. ${ }^{42}$ Each of them has influenced how the core commitments of cosmopolitanism are understood today. The first focussed on developing the idea of a shared community of all human beings in the poleis of ancient Greece. Here, the idea of global citizenship was already fully developed and central objections as well as important challenges to this idea were spelled out. The second phase enthusiastically developed this ideal further into specific aspects, some of which were even partly realised in some nations. The institutional arrangements within a nation that endorsed cosmopolitan Enlightenment ideas aimed to respect the equal moral standing of each individual citizen. Interestingly, it was the territorially defined nation-state that emerged as the prominent structure of political organisation during the Enlightenment period, and, as with the prior locus in ancient Greece, cosmopolitan ideals were sought largely "within borders". This did, however, explicitly include treating the citizens of other nations on one's own territory according to certain cosmopolitan standards. In a third phase, the implementation and realisation of cosmopolitan values began at a global scale, through an extension of economic

42 Of course, there are alternative narratives available, stressing different influences and phases, cf. e.g. Fine and Cohen (2002); for alternatives that stress non-Western traditions, cf. Giri (2006) or Appiah (2007). 
trade, and the installation of the first global institutions with specific legal arrangements. This is where we stand today. Progress has been made, albeit slowly. The diverse flaws of generally weak global institutions have even suggested to some that the cosmopolitan idea is without force, hopelessly utopian. It hence remains an open question: Will the refinement and realisation of cosmopolitan values in global institutions continue, and if so, how?

\section{The current debate on global justice. A brief overview}

Given global inequality levels, the degree of preventable deprivation, and the dynamics of global interaction, it is obvious that our world is unjust. The current debate about global justice in political philosophy and related disciplines aims to explain whether-and, if so, which-claims of justice hold at the global level. The point of departure in the debate is this question: To what extent can basic principles of social justice, which are widely shared at least within democratic nation states, be transferred to the global level? And if such a transfer is impossible, which other principles hold at the global level?

In this brief overview, I will introduce some basic distinctions and concepts that shape the current debate about global justice. This debate provides the background for the complementary debate about global political ethics dealt with in this book.

\subsection{The scope of justice}

Rawls's seminal book A Theory of Justice stipulates two principles of justice that ought to hold in a liberal society, and justifies them with the help of a contractarian procedure (Rawls 1971)..$^{43}$ In a hypothetical situation, which Rawls calls the "original position," the contract partners agree upon two basic principles of justice. They provide the reference to which different possible basic structures of societies can be compared, and through which the best possible, just, and fair order of society can be identified. This original position is characterised by the idea that all parties involved are under a "veil of ignorance". This means that they are free and equal persons ignorant of their own or any other contracting parties' personal characteristics, including sex, gender, 'race', religion, or social

43 Sections 4.1. and 4.2. of the present chapter draw on my contribution to a co-authored article (Heilinger and Pogge 2015). 
status in society, all of which Rawls, like cosmopolitans, regards as morally irrelevant. This way, the contracting parties make decisions about principles of justice independently of such morally arbitrary information about themselves, and any of their concomitant special preferences or interests. The principles of justice that, according to Rawls, result from such an ideal deliberation are the following:

(a) Each person has the same indefeasible claim to a fully adequate scheme of equal basic liberties, which scheme is compatible with the same scheme of liberties for all; and

(b) Social and economic inequalities are to satisfy two conditions: first, they are to be attached to offices and positions open to all under conditions of fair equality of opportunity; and second, they are to be to the greatest benefit of the least-advantaged members of society (the difference principle). (Rawls 2001, 42-43)

Rawls thus demands equality for all members of a society with regard to their basic freedoms. These include, among others, political freedoms (freedom of speech and assembly or active and passive voting rights), as well as freedom of conscience. Under ideal circumstances, inequalities with regard to these basic freedoms are, as a matter of principle, illegitimate. ${ }^{44}$ Furthermore, Rawls demands that all have fair, i.e. fundamentally equal, opportunities for holding attractive offices and positions. Fair equality of opportunity means that access to such privileges actually depends on a person's talents and effort and not on, say, her parents' socioeconomic position. If these two conditions are met, thus if all have equal amounts of basic freedoms and compete for offices under conditions of fair equality of opportunity, certain socio-economic inequalities-for example in property or income-may be acceptable. However, for this to be the case, another condition has to be met, namely that special concern is directed towards the worse off: unequal distributions are acceptable only under the condition that these inequalities make the worst off be as well off as possible.

The justification offered by Rawls for his focus on institutions largely depends on the profound influence such institutions have on the life prospects of people living in a society. ${ }^{45}$ Consequently, the principles of justice should

44 Under the conditions of non-ideal reality, however, Rawls allows for several exceptions; cf. Rawls (1971, ch. 4).

45 Rawls argues that "taken together as one scheme, the major institutions define men's rights and duties and influence their life prospects, what they can expect to be and how well they can hope to do. The basic structure is the primary subject of justice because its effects are so profound and present from the start. The intuitive notion here is that this structure contains various 
apply to these institutions as "justice is the first virtue of social institutions" (Rawls 1971, 3).

The publication of $A$ Theory of Justice initiated an intense debate on social justice in liberal societies which has yet to abate. Rawls's theory still figures prominently in these debates as an original version of "ideal theory" or, as he has it, as a "realistic utopia". Even if the principles are not fully enacted in any society on earth, it is imaginable and desirable from the point of view of a theory of justice that they be so; or so argues Rawls, who himself explicitly restricted the scope of his Theory of Justice to nation state-societies; in the international realm, different rules supporting peaceful cooperation among peoples and international assistance in cases of emergency apply (Rawls 199a).

Soon after the first publication of $A$ Theory of Justice, several scholars attempted to extend Rawls's liberal theory, and his contractarian approach, beyond the nation state to the international setting. Why should the principles of justice be only applicable within the borders of a state, they asked, but not on a global scale? Furthermore, it became more and more obvious that Rawls's understanding of nations as generally self-sufficient and isolated entities, no longer matched emerging political realities (cf. Buchanan 2000). This is why Beitz (1979) and Pogge (1989) considered in depth the possibility of a global extension of Rawls's contractarian model, and became influential thinkers in their own right. Their aim was to strive for social justice on a global scale (or cosmopolitan Rawlsianism). Contrary to Rawls's focus on the nation state, Beitz and Pogge endorse, in their respective accounts of global justice, a distinctively cosmopolitan perspective.

With this, the two poles between which the complex and diverse current debate on global justice unfolds can be distinguished. On the one hand are advocates of cosmopolitanism, who claim that substantial principles of justice exist on an international level and apply globally, similar to those at the domestic scale (cf. Gosepath 2001). These principles impose duties of justice upon both citizens and governments-e. g., with regard to the design and enforcement of supranational social institutions. On the other hand, there are defenders of particularism-or statism or nationalism, cf. Valentini (2011, 2)-whose aim is to restrict the duties of justice to the near range of a commonly shared institutional order. According to such views, a state's responsibility for just structures within its own territory has priority over any other possible moral or political responsibilities in

social positions and that men born into different positions have different expectations of life determined, in part, by the political system as well as by economic and social circumstances" (Rawls 1999b, 6-7). 
global relations. Both positions, cosmopolitanism and particularism, are not only important to political philosophy but also have implications for the field of ethics, for example with regard to the determination of individual agents' moral duties. In the following, I will explore the assumptions basic to both positions.

\subsection{Cosmopolitanism vs. particularism}

Above, I mentioned three normative properties defining cosmopolitanism: normative individualism (every single human being-and not, say, groups or states -is of ultimate moral importance); egalitarianism or impartiality (every single human being is of equal moral importance, all have the same moral status and, accordingly, the claims of all need to count equally); and universalism (all human beings stand in relations of justice to one another, which are comparable to the relations between citizens of a state). On the basis of the assumption of moral equality, cosmopolitanism demands of moral agents, at least prima facie, that they grant unknown people from other countries the same moral importance as their compatriots and people in their near range. What practically follows from cosmopolitanism is, on the one hand, an obligation that every single moral agent consider (and act to prevent or limit) the harm of faraway people and, on the other hand, the requirement that, in an institutional way, it be guaranteed that the interests of all human beings are given the same weight.

These considerations point toward the possibility of several variants of cosmopolitanism: first, there is moral cosmopolitanism, which focusses on the moral rights and duties of individuals in the international context. This must be distinguished from political or institutional cosmopolitanism, which focusses primarily on the rights and duties of political institutions. A third form of cosmopolitanism shall at least briefly be mentioned, namely cultural cosmopolitanism. Here, rights and duties of individuals or institutions are of lesser importance than the development of cultures in the age of globalisation. Cultural cosmopolitanism opposes assumptions of static cultural "purity" and emphasises that cultures necessarily develop through dealings with other communities and changing environments. Such cultural changes, and the emergence of hybrids of different cultures are, according to cultural cosmopolitanism, the adequate response to a globalised world (cf. Waldron 2000).

Moral and political cosmopolitanism also come in different shades according to how strong the normative demands are formulated. One can distinguish a "moderate" version from a "strict" version of cosmopolitanism. "Moderate" cosmopolitanism only holds that all human beings are of equal moral impor- 
tance and have fundamentally equal claims of justice to conditions of a minimally decent life, without, however, placing any particularly demanding obligations upon those who are capable of realising these conditions. As so little is gained from such a position, it has been criticised as only minimally insightful (Miller 2002). "Strict" cosmopolitanism, on the other hand, demands of all agents that other human beings be treated equally for their equal moral status. This, in turn, may lead to extreme demands upon moral agents, which are practically impossible to discharge and therefore implausible (Miller 2002, Pogge 2007, 328).

In contrast to cosmopolitan views, particularist positions stipulate a restricted scope for the application of principles of justice, usually to the nation state. Moreover, particularism attaches special moral importance to group membership. Accordingly, it is at least morally permissible, and sometimes even demanded, that greater moral weight be assigned to the interests of people in the near range. The moral rights and duties in the near range thus differ from those on the global level. Examples are the special moral weight of family members and friends for an individual agent, or the preferential treatment of a state's citizen by its institutions, both of which imply a particular responsibility for certain (groups of) people and, at the same time, a lower responsibility for those who are not family members, friends, or compatriots. According to particularists, cosmopolitanism fails to capture this commonly held and rarely questioned intuition about the fundamental and important moral difference between all human beings and those nearer and dearer to an agent (Miller 2002).

Particularism hence contains three normative features:

- Egalitarianism/Universalism: Just like cosmopolitanism, particularist positions also hold that all human beings have the same fundamental moral status, and they oppose discrimination by sex, skin colour, nationality, etc. There is, in short, no difference between particularist and cosmopolitan views on this matter, and barring extreme views-racist, sexist and otherwise (with which I do not engage)-egalitarianism is now very broadly accepted and endorsed. The substantial differences between cosmopolitan and particularist views do not lie in the basic conviction that all human beings are equally important moral subjects, but rather in the question of what exactly follows from this assumption. In particular, there is disagreement on what instances of unequal treatment and unequal distribution can be justified in light of the equal moral standing of all.

- The particular importance of groups: Instead of endorsing normative individualism, particularists hold that groups of people may have moral value and can give rise to genuinely particular duties of justice. A family, a club, or an entire country, have genuine intrinsic value, independent of the instrumental value of the advantages that membership confers on those in the 
group. The actions that enact this value must be morally acceptable. In this vein, Miller has argued that certain forms of preference and partiality for compatriots are legitimate-which implies that diminished obligations exist towards non-compatriots (Miller 2005).

- Restricted scope of justice: Particularists hence argue for more constrained principles and duties within certain groups. A normative argument for restricting the scope of justice to the state level is that justice in the narrower sense is understood as a property of institutions (Rawls 1971, 3). The realm of individual action between individuals, or the realm of international interaction beyond national borders, where there is no superordinate institutional order, is consequently excluded from the evaluation via established principles of justice (Nagel 2005). A consequence of this position is that-at least as long as there is no global institutional order-there will be no relations of justice (in the narrow sense) on a global level. The rights, for example, of people suffering from hardship within a poor country engage only that state's institutions (however weak they may be), and only in certain exceptional cases (such as historic tort) can there be claims upon other, richer states or their citizens. If wealthier countries choose to help the poor in other countries, this certainly is, according to particularists, a morally praiseworthy act of assistance, but would not constitute the discharging of a duty of justice.

Particularism presents a position that closely matches the status quo reality of our current world of nation states. Cosmopolitanism, on the other hand, appears more idealistic and utopian. Because of this, particularism can be seen to provide a moral justification of the existing state of global affairs.

In their extreme and purest forms, neither strict cosmopolitanism nor strict particularism are particularly convincing. Both neglect important insights that figure prominently in the other. That I should treat a person I do not know from a country I have never heard of in the same way as I treat my own child is just as implausible as the assumption that Japan's public health insurance ought to cover the medical costs of Mexican patients in Mexico. On the other hand, it is also implausible to think that special concern for the already welloff people in my in-group should be able to trump the most basic needs of people who happen not to be members of my group; it is also implausible that norms of justice must generally remain confined to contingent entities like states.

Applied to concrete cases, for example of world poverty or inequality in access to health care, the extreme positions often contribute very little in the way of helpful and practically relevant guidance. Extreme cosmopolitanism is quickly 
dismissed as utopian and unrealistic, and strict particularism often is not even capable of acknowledging why a duty of justice beyond mere voluntary generosity should exist towards distant strangers and states in the first place. The most interesting debates today are thus found in between these two poles, and have to do with approaches to accommodating both cosmopolitan and particularist intuitions.

\subsection{Metrics and patterns of just distributions}

According to the (Rawlsian inspired) understanding of justice as a virtue of institutions, a prominent question is how these institutions distribute the advantages or goods people need in order to live a good life. This question is pertinent on both the domestic and the global level. A central element of the debate on global justice is hence the distributive question: Who should get how much of what? Rawls has suggested a distinctive distributive theory of justice in which basic social goods are distributed equally, while economic inequalities are acceptable if and only if the unequal distribution occurs under conditions of fair equality of opportunity, and if and only if the unequal distribution is altogether maximally beneficial to the worst-off in society. Rawls's theory of justice hence answers the question of what should be distributed (social primary goods, opportunities and economic resources) and how it should be distributed (equally and with special priority to the worst off). His answer indicates that there are several options with regard to the two question about the "currency" or "metric" of justice on the one hand and about the "patterns" of distribution on the other.

Let us focus on the "currency" or "metric" of justice first. Is the advantage to be distributed a resource (like fundamental rights), or an all-purpose economic good (like money), or is it actual well-being, or opportunities to achieve certain goods, or is it still something else? I will mention the main answers to this question of what should be distributed, since they play a particularly important role in the current debates about global justice. ${ }^{46}$

To provide an admittedly simplified reconstruction of the ongoing complex debates, one can distinguish three main views when it comes to answering the question what should be the currency or metric of justice, or what should be distributed in a certain way in a just society: resources, welfare or capabilities/functionings. Resources and capabilities can be called “objective” metrics of justice

46 For this brief overview over a very fine grained and complex debate I rely on Anderson (2010c), Arneson (1989), Dworkin (2000), and Brock (2011). 
because they determine justice by referring to objectively measurable states of individuals or their possessions; well-being, on the other hand, is a subjective metric since it relies upon the subjective evaluative states of individuals with regard to their happiness or preferences (Anderson 2010c, 85). I will only briefly review these metrics and, for introductory purposes, will assume that we aspire to achieve such an equal distribution. I will then complicate matters, towards the end of this section, by briefly mentioning alternatives to this pattern of distribution: besides equality one could consider priority, sufficiency and adequacy as patterns.

As an obvious candidate for determining what should be distributed in a certain way in a just society, resources come first to mind. Resources are an objective metric of justice since they can be externally assessed and measured (Dworkin 2000). In Rawls's theory, which is fundamentally resourcist, the social primary goods are a way of spelling out the basic needs of individuals. Accordingly, the distribution of social primary goods is what matters for a just society. The basic goods Rawls lists are diverse and include rights (both civil and political rights), liberties, income and wealth, the social bases of self-respect, and others. Often, the distribution of money is taken as a valid proxy for assessing the distribution of resources generally, since money, as an all-purpose good, can be easily transformed into several different goods according to the preferences of the agent.

Yet, there are problems with distributing resources that have led some to claim that it would be preferable to be concerned about a just distribution of actual well-being. A first obvious problem is that equal amounts of, say, money, do not secure that people are equally well off. Let us assume that two people, A and $B$, have equal preferences and generally equal abilities, but that B suffers from a physical handicap that makes it necessary for him to rely on costly medical aid to move. An equal distribution of resources to both will disadvantage B significantly since he would have to spend much of his available resources to establish his mobility which A gets "for free," such that A has more resources available to promote his interests.

Dworkin, a defender of resourcism, discussed this objection and suggested, as a way forward, that personal endowments and talents be included among the resources that are to be distributed equally (Dworkin 2000, ch. 2).$^{47}$ Focussing on actual external resources like money fails to take into account such personal resources. But Dworkin's suggestion faces a problem, as he acknowledged himself:

47 Rawls had excluded these goods, which he called natural primary goods (intelligence, imagination, health, etc.), from being taken into account for an equal distribution. 
the "slavery of the talented" objection (Dworkin 2000, 90). If personal inborn differences are to be counted among the resources to be distributed, those with better endowments might be compelled to give away their resources indefinitely in order to compensate those with lesser endowments. This, however, would result in a relative disadvantage, and even some kind of punishment for those who are born with talents. But punishing people for something which is completely beyond their control, is morally objectionable. So, measuring distribution in terms of resources faces significant challenges and might generate counter-intuitive, even unjust requirements.

Against resourcism, others have claimed that measuring the actual welfare of people provides the appropriate metric of justice. ${ }^{48}$ Welfare could be understood as the actual well-being or degree of happiness of a person, but in the debates about utilitarian standards, the satisfaction of ideally considered preferences has proven to be superior to the rather blunt standard of happiness ("preference utilitarianism"). Again, space constraints here rule out an extensive discussion of the many difficulties raised by establishing such standards, but it is clear that, as the metric of justice, comparing the welfare of people has some important advantages over comparing the resources available to them, since this places the focus on what matters most, which is on how people are actually doing. But here yet another problem appears, since people can end up with very different states of well-being simply by virtue of their reasonable choices. Would it then be appropriate to distribute the necessary means to achieve certain levels of well-being in such a way that also "expensive" preferences of people are met? What if I have an acquired taste such that only eating caviar makes me happy? What if my decision to be politically active and to improve the situation of the poor in my country counts more for me than my personal motivation to achieve levels of welfare? Should people be forced to reach certain levels of well-being if this is the metric of justice? Such questions indicate that actual levels of welfare might also be quite far from being a suitable metric of justice.

These challenges have led some to defend opportunities for achieving welfare (Arneson 1989) or capabilities to achieve functioning (Sen 1992) as the metric of justice, which indeed offer a particularly fruitful way of measuring justice. Arneson writes: "An opportunity is a chance of getting a good if one seeks it" (Arneson 1989, 85). He explains further that equal opportunity for welfare among a number of persons demands that each person encounters equivalent sets of op-

48 This view presupposes that it is possible to make sound interpersonal comparisons of subjective mental states, which will, of course, be more difficult than to compare objective resources, but let us assume that this is possible. 
tions to achieve satisfaction of his or her rational preferences. They do not have to be the same options, but overall they have to add up to the same prospect of achieving well-being. People do not have to end up achieving the same levels of well-being, but they are to have equal opportunities to do so. It will be still up to the individuals themselves to decide and to act freely. The development of personal preferences and decisions (for example to trade well-being against other goods, such as the pursuit of political activism) are still available to individuals.

The capabilities approach, developed by Sen and Nussbaum, offers a structurally analogous way of determining the goods that are to be distributed in a just setting. Here again, the advantage in question is not the actual fulfillment or the actual exercise of certain actions, but the capability, i.e., the real opportunity to do or be what is valued. ${ }^{49}$ This freedom to achieve functioning is of primary moral importance, because it not only captures well-being and advantage but also the "well-being freedom" that itself contributes directly to well-being.

Among capability theorists there is a great deal of dispute about whether it is necessary to provide a comprehensive list of capabilities in order to be able to assess and compare individual well-being, and the various forms of social arrangements under which individuals do (or conceivably could) live. Sen has denied this need of the capability approach, and has defended its "incompleteness" (Sen 1992, 46), while Nussbaum has repeatedly suggested a list of basic capabilities, among them life, bodily health and integrity, practical reason, affiliation, play, and control over one's environment (e.g. Nussbaum 2006, 76-78).

The notion of "well-being freedom" (Sen 1992, 40), central to the capabilities approach, captures well the advantages of this view ${ }^{50}$ : it is not narrowly focussed on the distribution of resources but concerned with people's actually accessible options, while still leaving room for the individual preferences and decisions of people who may often be willing to exchange higher levels of personal wellbeing in order to achieve other goals. ${ }^{51}$

49 Terminologically there is an important difference for capability theorists between the "functionings," i.e., the "beings and doings" of a person, his or her states and activities on the one hand, and the "capabilities," i.e., a person's (set of) real freedoms or opportunities to achieve certain functionings. Capabilities are hence the effectively possible valuable opportunities available to a person.

50 This holds true for both its "incomplete" and its "determined" variant, and also for the opportunities for achieving welfare approach.

51 Already here, I want to hint towards a critique of the largely resourcist accounts of luck egalitarianism that will figure prominently in chapter two below. According to criticism by Anderson (1999), the focus in theories of justice about matters of distribution misses the fundamental point of the idea of egalitarian justice. It is not of prior importance to determine who should get how much of what, but it is important that people interact with one another as equals, 
Of these three different attempts to define (non-relational) goods that must be distributed in a certain way in order to be just, the capabilities approach is the one which is most closely related to relational theories of justice, since it aims to secure the possibility for each to develop his or her human capacities undominated by others. But, in order to fully cover the current debate about justice, let us turn to the different patterns according to which certain types of advantage (which we now know can be expressed in different metrics or currencies of justice) can or should be distributed.

Assuming that a decision in favour of any one of the different goods has been made, what exactly would we want the distribution of that good to look like? Which "pattern of distribution" should be aimed for? Generally, there are three main options available. First, it could be claimed that each individual should have equal shares of the respective good. ${ }^{52}$ Such an egalitarian intuition comes to mind quickly, but is subject to the notorious "levelling down objection," which points out that equality can also be reached by diminishing everyone's level of advantage to the level of the worst off. Alternatively, it could be claimed that inequality is not problematic per se, but only when it is so severe that the worst off are very badly off indeed, and thus deserve special concern and attention. All distributions thus should assign priority to those worse off than others. Such a prioritarian pattern of distribution has been defended, among others, by Parfit, and also by Rawls. ${ }^{53}$ Third, it can be argued that inequality is not always problematic and that giving priority to the worst off is also at least sometimes not the point (e.g., if the least advantaged are already extremely well off), so that the prior concern of justice should be in promoting that all have enough (for living a minimally decent life). Such a sufficientarian view stipulates a threshold to be reached by all, above which certain degrees

which would lead them to resolving questions about distribution in cooperative ways. From this perspective, generally known as a relational view, matters of distribution are less important for theories of justice than are matters of how people interact with one another (whether people interact with one another as equals or within hierarchies where some are oppressed, dominated, silenced, etc.). Distributive inequalities are often symptomatic of underlying inequalities in social standing and, of course, massive inequalities that place some below a reasonable threshold of sufficiency are of particular concern for relational theorists. The relational view has significant distributive implications of course, but the core concern for relational theorists of justice is not the distribution of advantage but the quality and the structures of interaction.

52 Prominent egalitarian views can be found in Rawls's first principle of justice (Rawls 1971), in Arneson's defence of equal opportunity for welfare (Arneson 1989) and in Dworkin's theory of equal resources (Dworkin 2000).

53 Rawls's difference principle claims priority for the worst off (Rawls 1971); cf. also Parfit (1997). 
of inequality are acceptable. ${ }^{54}$ Among sufficientarian approaches, there is ongoing debate about the formulation of more ambitious "adequacy" thresholds (cf. e.g. Satz 2007). These would not just call for a minimally decent threshold but set more ambitious demands that would allow people to live a more than minimally decent life, to be functioning well as full citizens in a democratic society (Anderson 1999), or maybe even as global citizens in the world (see below, chapter two, section four).

\subsection{Global structural injustice}

The introduction already briefly mentioned structural injustice as a particular moral wrong which systematically disadvantages large groups of people while others are enjoying privileges that are generated at the expense of the disadvantaged people (Young 2011). ${ }^{55}$ Global structural injustice is characterised by three particular features. First, the distinctive metric of structural injustice is the quality of the relations and connections between people that is shaped by inequality, hierarchy, systematic exploitation and domination. However, unequal distributions of resources and welfare can also be indicative of relational inequalities. The second feature is, that this form of injustice is deeply embedded in social structures. A structure can be understood as "a set of rules and resources recursively implicated in the reproduction of social systems in a way that both presupposes and creates certain patterned constraints on agents' positions and on the degree of social and political power that they control" (Ypi 2017, 9). The place of structural injustice hence consists of the acts and interactions of persons in a shared social framework, encouraging or disencouraging certain patterns of individual or collective behaviour through mechanisms like social expectations or economic, political or legal regulations. Such structures exist not only within the domestic sphere but they extend, in an interconnected world, around the globe. A third distinctive feature of structural injustice is that such injustice can occur without malevolent intent and without causally decisive and identifiably culpable behaviour. Instead, such injustice is deeply embedded in the accepted social background conditions of peoples's lives and may result from apparently innoc-

54 Cf. Anderson (1999), Frankfurt (1987), and Nussbaum (2011a). For an overview, cf. Fourie (2017).

55 A much discussed example are global economic interactions linking workers producing apparell under exploitative conditions with consumers elsewhere. Cf. below, chapter four, section four. 
uous actions and decisions, when people or groups of people follow their seemingly unproblematic and fully legal preferences. The injustice in question is hence often a problematic result of the behaviour of persons who do nothing which they would consider particularly wrong. ${ }^{56}$

Three main strategies can be distinguished to justify that the privileged individuals bear moral responsibility in the face of global structural injustice: individuals can be said to have contributed to causing or upholding the problem; they can enjoy unjustified advantages; and they can be in a position to contribute to ending a severe moral problem. The underlying idea for each strategy is that a morally relevant connection or relation exists between the disadvantaged and the advantaged people generating responsibility for members of the advantaged group, i.e. the rather affluent, morally sensible, well-informed and capable citizens in the industrialised countries of the Global North. These connections, however, are of very different kinds.

Many of the large scale problems, particularly the consequences of climate change and the injustices in the global market, are influenced by aggregated individual behaviour. While probably no-one intended to cause global warming by greenhouse gas emissions, all those who contributed to the increase of greenhouse gases in the atmosphere are - albeit only in a minuscule way-part of the group that collectively caused the problem at hand. It has been subject to debate whether such minuscule contributions that in themselves do not cause any measurable or perceptible harm generate some kind of moral responsibility. But a strong argument from tort law can be put forward to justify responsibility also in these cases: as a member of the group whose collective behaviour caused a problem, one is a "necessary element of a sufficient set" and hence also personally, causally responsible for its existence (Wright 1985). Being part of the problem (even if the problem would not be solved had one acted differently) assigns a share of causal responsibility to all persons involved, and as such those who have caused the problem should also bear a responsibility to deal with it and to provide solutions (Barry and Macdonald 2016). This holds true even if individual agents cannot be said to have been contributing to bringing the problem into existence in the first place: Even if their actions contribute only to upholding the problem, they are entangled in it and bear moral responsibility both for its persistence and for addressing it (Pogge 2008).

56 This, of course, does not exclude the possibility that global structural injustice may in some cases result from or be increased by careless or straightforward malevolent actions; cf. the discussion in Young (2011). 
Such connections-and the resulting relations of responsibility-become clearer and weightier, if the problematic structures are seen as conveying unjustified advantages to some-at the cost of corresponding, unjustified disadvantages suffered by others. The opportunities of citizens in high-income countries (e.g. to drive in polluting, private cars or to purchase cheap clothing or to vacation in low-income countries) are a flip-side of limited opportunities of others elsewhere (who have, e.g., to deal with rising sea-levels, have to work in factories under sweat shop conditions, or whose economies are disadvantaged by international trade regulations). On this account, it is simply inadequate to limit the normative assessment of the quality of citizen's actions to the immediate outcomes in the near range: the complex global background-conditions need to be considered as well; if they appear as morally dubious, even massively unjust, then the seemingly innocent activities of well-intended citizens in Western societies become morally questionable. The enjoyment of unjustified advantage thus indicates specific connections and responsibilities (Butt 2007, Calder 2010). Iris M. Young's seminal argument from "social connections" is the paradigmatic version of this argument: The ongoing social connections that constitute the shared framework of structurally unjust interaction establish a link of responsibility between the beneficiaries of these structures and those suffering the generated disadvantages (Young 2011).

Another type of arguments for individual responsibility-more controversial than the preceding ones because it assumes only a loose connection between the advantaged and the disadvantaged-is not based on any claims about actual social or causal connectedness or the enjoyment of advantages. Rather, it stipulates the sheer ability to help someone in distress to be sufficient to generate some degree of personal responsibility to do so. ${ }^{57}$ Given the urgency of the need of a disadvantaged person or group, being capable of addressing it constitutes already a morally relevant relationship and connection: the fact that someone's fate existentially depends on what an agent does establishes a relation, even though an asymmetric one in which only one side has the privilege to act about the disadvantage or need in question. Such a relation, shaped by unilateral vulnerability, persists even if it is not developed further; i.e. when those who could initiate an actual interaction remain passive. Yet, refusing to take action does not eliminate the channel of connection. In such cases, omissions to act should be understood as passive contributions to global structural injustice.

57 In the context of human rights, for example, Sen argues convincingly: "Human rights generate reasons for action for agents who are in a position to help in the promoting or safeguarding of the underlying freedoms" that go "beyond volunteered charity or elective virtues" (Sen 2004, 319). Cf. also Griffin $(2008,102)$ and Ashford (2007). 
These different connections or relations, often hidden or unacknowledged, link those suffering from the structural injustice in question with those who are better off and, in consequence, justify individual, forward-looking responsibility.

In sum, the notion of global structural injustice provides a concept pointing to the often hidden connections between the advantages enjoyed by some and the disadvantages suffered by others. As such the diagnosis of global structural injustice helps one to see through the surface of morally problematic states of affairs to the fundamental structures generating them within a shared system of interaction. The relevant form of injustice in the case of global structural injustice is primarily relational, not distributive: it is about relationships of domination, of privilege, power and exploitation, which, as part of social patterns and structures, do not have to follow from malevolent intent. Subsequent distributive inequalities - with regard to income, wealth, access to resources and opportunities for example-are indicative of these fundamentally relational inequalities. Given the complexity of global structural injustice and its deep rootedness in widely shared standard patterns of interaction and behaviour, remedying them will certainly be difficult. Significant political and social reforms leading to institutional and individual changes in interaction and behaviour seem to be necessary. However, the massive and obvious institutional shortcomings in effectively addressing global structural injustice point to the question of whether nothing else can be done or whether there are no other bearers of responsibility. Or, to put it more concretely: What is the role and the responsibility of individual persons in fighting the distinctive wrong of global structural injustice?

\section{Global justice and global ethics}

Now more than ever, it is necessary to address the signature challenges of our globalised world-global poverty, global inequality, global warming and climate change, global trade etc.-from an institutional perspective with a focus on the role of institutional agents, international agreements and structures of interaction. Nevertheless, it is not my ambition to contribute to this side of the debate. Rather, the catastrophic global state of affairs provides the relevant normative background for my project. While we see that the current institutional system does not prevent massive inequalities nor secures sufficient well-being for all, and while the important debate continues about how feasible and effective institutional arrangements would look like, more focus is needed on the role and responsibility of individual agents right now. While it is clear that many (institutional and individual, collective and national) agents fail to do what is 
necessary in order to solve the problems we face globally, this must not serve as an excuse for individual inaction which can be understood as "passive injustice". ${ }^{58}$ Rather, the question is: How should-capable and willing-moral agents think about their roles and responsibilities in a world which is shaped by ongoing injustice? How should we determine the moral demands we are subject to in the absence of a just world order?

In other words, the challenge is to develop a global ethics to guide individual actions in a world in which global justice is (as yet) out of reach. This individual ethical dimension is under-explored in current debates about global justice, which continue to suffer from Rawls's decision to focus on institutional arrangements at the cost of neglecting the role of individual agents. I want to stress again that my interest lies in complementing such ongoing debates with an analysis of the role of the individual, without denying the importance of institutional concerns. It is not a shortcoming of these debates that they have such a focus, but in a time when meaningful success on the global institutional level appears distant, it is important to dedicate attention to individuals, their actions and their inaction, as a possible additional avenue for seeking such progress. In this section, I will first explain my view on the relationship between institutions and individuals, before discussing the possibility and the limits of a meaningful division of moral labour in the present context.

58 The claim that inaction under conditions of structural injustice is morally problematic is also supported by Judith Shklar's concept of "passive injustice" which can be found among those who could and should be doing something about it. Passive injustice is a distinctively civic failure if citizens "fail to stop private and public acts of injustice" (Shklar 1990, 6). Such passive injustice goes beyond the basic general indifference one might have towards the suffering and misery of others, because it presupposes the existence of relationships in a shared framework. Shklar explains: “As citizens, we are passively unjust [...] when we do not report crimes, when we look the other way when we see cheating and minor thefts, when we tolerate political corruption, and when we silently accept laws that we regard us unjust, unwise, or cruel.” (ibd.) While Shklar discusses the concept of passive injustice in a domestic, I contend that it is also applicable to the global domain, when "citizens of the world" tacitly tolerate and accept structures, laws, and patterns of international interaction that are shaped by domination, exploitation and thus systematically disadvantage large groups of people. Those enjoying the corresponding advantages, if they fail to acknowledge these processes and do not speak up against them, even deny the existence of such problematic relations, are in their passivity integral and constitutive elements of the injustice, they become silently complicit. 


\subsection{Individuals and institutions}

The relationship between individuals and institutions is complex and I cannot here do justice to the intricate debates in sociology and social ontology. But I contend that individuals are ontologically and morally prior to institutions, where the latter are understood as complex social forms that emerged over time in social life, with an ability to reproduce themselves and to endure (cf. Miller 2014). This claim is meant to support the importance of directing attention to the role and responsibilities of individuals to promote justice even though one would, under more ideal circumstances, wish that institutions deliver it. The notion "institution" itself is ambiguous and refers to diverse phenomena, such as governments, the family, universities, hospitals, business corporations, and the legal system, all of them shaping social practices, i.e. the ways individuals behave and interact. Institutions, however, have been brought into existence over time by humans, sometimes more and sometimes less intentionally, most often in order to serve specific purposes. Frequently, those purposes have to do with some sort of individual or collective human need. Here is an example: the need to get mail carried from $a$ to $b$ is the point of the institution of a postal service. In order to secure a task effectively without obliging everybody to do it her- or himself, work can be organised, divided and distributed to some, with the help of an institution. This implies conversely that without a need of persons to have their mail taken from $a$ to $b$, there would be no point for the institution of postal service. Frequently, institutions mirror existing (problematic) power structures, examples would be the institutions of monarchy or the caste system. And the absence of institutions can indicate a lack of interest or commitment to a certain cause. So, existing institutions require scrutiny, and identifying unmet needs and social problems invites considering the creation of institutions.

One upshot of this understanding of institutions is that they do not have an independent "life" of their own, detached from individual persons. Ontologically, institutions depend on persons for at least two reasons: because individuals's needs and acts led to the creation of institutions in the first place and because individuals uphold institutions. ${ }^{59}$ I find this priority of individuals also expressed in the writings of Dewey who claims: "Instead of thinking of our own dispositions and habits as accommodated to certain institutions we have to learn to think of the latter as expressions, projections and extensions of habitually dom-

59 In cases where institutions develop a "life" on their own, like a hyper-bureaucracy as described in Franz Kafka's writings, individuals feel alienated and objectified. Yet, this is rather a perversion of the original function and point of institutions, and this possibility of things going awry does not speak against my claims. 
inant personal attitudes” (Dewey 1939, 226). Also in the context of debating moral questions, individuals can be understood as remaining the primary bearers of responsibility. Nussbaum has made a similar argument in the context of her capabilities approach. She writes: "Institutions are made by people, and it is ultimately people who should be seen as having moral duties to promote human capabilities.” (Nussbaum 2006, 307).

The lasting importance of individuals in the functioning and shaping of institutions backs my claim about the ontological and moral priority of individuals. Institutions, as patterns of human behaviour or interaction, need actual humans to fill them with life. This, however, provides individuals with the constant possibility of transferring their individual spirit or ethos to the institutions which they comprise. Of course, the bigger and the more established institutions become, the bigger becomes their inertia and the smaller becomes the potential impact of any single individual attempting to influence an institution's functioning. But individuals remain responsible not only for bringing the right institutions into existence. In the case of already existing institutions, they remain responsible for influencing their functioning in the right way.

The basic distinction between individuals, individual agency and the realm of ethics on the one side, and institutions, institutional agency and the realm of justice on the other, serves as a helpful starting point for structuring an immensely complex debate about different agents of and responsibility for (global) justice. Yet, as we will see, there is significant overlap between both sides: institutions and social backgrounds influence individual behaviour; and individual acts shape social and institutional arrangements. The influence between individuals and institutions is mutual. ${ }^{60}$ Thus, when institutional action is absent or inadequate to reach some sufficiently important goal, individuals themselves are ultimately called upon to secure what, under ideal conditions, could fall under the responsibility of an effective institution (e.g. realising justice or securing basic needs of other persons). A global ethics, outlining the responsibilities of individuals, hence is-at least for the time being under non-ideal conditionsan important complement to theories of global justice.

60 More on the individual ethos of a person, understood as an intra-personal 'institution,' in the concluding chapter below. 


\subsection{The division of moral labour}

The analysis of the role and responsibilities of individual agents is pertinent also in the debate about a possible "division of (moral) labour" with regard to realising (global) justice. Maybe some tasks can be taken over by institutions, others by individuals, so that in some cases some agents are not called upon? Rawls gave an important impulse to this debate for the domestic context. He defended the need for a division of moral labour-for separating principles for just institutions from rules for individual conduct-as a consequence of moral pluralism. ${ }^{61}$ "The principles of justice for institutions must not be confused with the principles which apply to individuals and their actions in particular circumstances. These two kinds of principles apply to different subjects and must be discussed separately" (Rawls 1971, 54-55). Once there are adequate institutions within a just 'basic structure of society,' individuals are allowed to "lead their lives in such a way as to honour the [different] values appropriate to smallscale interpersonal relationships" (Scheffler 2005, 236). ${ }^{62}$ And indeed, institutions and individuals are distinct entities and types of agents, and thus it seems implausible to demand that both act exactly in the same way guided by exactly the same rules and principles. On the other hand, however, one could ask why the same basic aims, values, and principles of justice, if they are sufficiently important, should not apply to both types of agents, individual and institutional, even if their respective obligations will be different in kind. Specifically, one should ask: Should individuals be morally permitted to neglect their individual roles and their possible contributions, however minimal, to addressing massive social and global problems of justice? Are they allowed instead to confine their moral concern to the values and challenges of their own personal, individual lives and immediate surroundings? In other words, what should a possible division of moral labour look like if adequate institutions to secure justice are absent?

61 See Scheffler's reconstruction of Rawls's original argument (Scheffler 2005, 237-240).

62 Elsewhere, Rawls argued that the "principles of justice, and in particular the difference principle, apply to the main public principles and policies that regulate social and economic inequalities. They are used to adjust the system of entitlement and earnings and to balance the familiar everyday standards and precepts which this system employs. [...] It applies to the announced system of public law and statutes and not to the particular transactions and distributions, nor to the decisions of individuals and associations, but rather to the institutional background against which these transactions and decisions take place” (Rawls 1996, 282-283, my italics). 
Rawls's argument exposes his rather narrow focus on ideal theory, inquiring about what a just society would look like and considering what is demanded from different agents in these circumstances. ${ }^{63}$ But since we cannot assume that our current social or global arrangements are already just, this account does not suffice: it remains silent when it comes to determining what agents are obliged to do under circumstances that are dramatically unjust. Pointing out that individuals may under favourable circumstances legitimately place value on the pursuit of their personal interests appears to me as potentially misleading and overly lenient in the face of the urgency of the problem of global injustice and in the face of the possible impact of individual action. ${ }^{64}$

Thus I contend that, if the institutions, laws and norms necessary for establishing justice are either inexistent or ineffective, the goal of justice should be directly taken on by individuals. The value of justice in itself is sufficiently important to demand action from whoever is able to do something about it. And even a possible division of labour that would provide individuals with more discretion, once just and effective institutions secure justice, would not let individuals off the hook.

\subsection{Towards an egalitarian ethos}

Cohen has criticised the implications of Rawls's theory of justice and the suggested division of labour. Against Rawls, he underlined the importance of an "egalitarian ethos" held by the individual members of a just society. Cohen famously asked, if you are an egalitarian, how come you are so rich?, and in doing so exposed the double standard applied by many rather affluent individuals when they hold egalitarian views but do not consistently act according to them (Cohen 1997, 2000, 2008). Cohen criticised Rawls for permitting individuals unlimited self-interest in economic choices, as long as it takes place within a just basic structure and respects the rules and laws of such a society (Cohen 1997, 16). Rawls's division of labour limits the demands of justice to institutional

63 For the distinction between ideal theory and non-ideal theory, cf. Simmons (2010) and Valentini (2012).

64 "If this division of labour can be established, individuals and associations are then left free to advance their ends more effectively within the framework of the basic structure, secure in the knowledge that elsewhere in the system the necessary corrections to preserve background justice are being made” (Rawls 1996, 269). This view has triggered Cohen's objection against Rawls, more on which in the following section. 
agents and hence lets individual agents off the hook too quickly. ${ }^{65}$ The "egalitarian ethos" defended by Cohen would motivate individuals to act according to the values endorsed in the theory of justice. Such an "ethos of justice" would then also "inform [...] individual choices" (Cohen 2000, 128).

But how should an "ethos" be understood? Wolff has offered a useful and concise characterisation of an ethos as

\begin{abstract}
a set of underlying values, which may be explicit or implicit, interpreted as a set of maxims, slogans, or principles, which are then applied in practice. As an idealization we can identify three levels: values, principles, and practice, all of which are part of the group's ethos. Typically the values and principles will be internalized by members of that group, and inform their behavior. We can talk of the ethos of a particular society, or of a smaller group, and can raise the question of whether, and how strongly, a particular individual shares the social ethos in question. (Wolff 1998, 105)
\end{abstract}

With this definition in mind, I agree with Cohen's views and stipulate an ethos of cosmopolitan responsibility as the appropriate and motivating attitude to be adopted by individual moral agents in the face of global issues. While Cohen originally showed the need for an egalitarian ethos under the condition of a society already organised according to principles of justice (and with coercive rules for institutional conduct and the economic transactions between individuals already in place), it should be clear that such an ethos is needed even more urgently if such rules are absent ${ }^{66}$, and this holds true on the domestic as on the global level. Nevertheless, as I will argue below, promoting such an ethos does not have to mean that everybody has to take up every problem on this planet individually - even though, according to the idea of cosmopolitanism, all relevant problems in the global context do concern and oblige all agents in some way. A division and distribution of the required moral labour between different types of agents-different institutions and different individuals-will still be in line with cosmopolitan thinking, if the idea of a morall relevant community connecting all as equals is upheld. Possibly, it will even grant individuals choicesmaybe along the lines of reasonings about feasibility and effectivity, but perhaps

65 While I share Cohen's conclusion that individuals have to develop an egalitarian ethos which also informs people's private economic choices, his general criticism of Rawls seems slightly exaggerated to me, since Rawls repeatedly indicates (even though I feel that this aspect is underexplored in his institution-focussed theory of justice) that individuals also play a role in supporting just institutions and bringing them into existence (cf. Rawls 1999b, 93, 99, 231, 398, 415, cf. Scheffler 2010, 131).

66 See also Young (2011, 67-68). 
also taking into account contingent facts about personal preferences-about which issue to tackle with how much energy.

Such an understanding of a division of labour, however, differs significantly from Rawls's own proposal, insofar as my suggestion does not liberate individual agents from anything. Quite the contrary: in light of both the circumstances of our unequal world, and the obvious limitations of the Rawlsian division of moral labour under non-ideal conditions, it is part of the problem that individuals are too easily let off the hook and and that they quickly seize the opportunity to imagine their inaction as morally justifiable. These practical considerations will be explored further in the second part of the book.

This chapter introduced the long and rich tradition of cosmopolitanism and portrayed important concepts and distinctions from the current debate about global justice. Cosmopolitanism was presented as a distinctive normative stance that conceives of all humans as morally equal citizens of the world. This (self-) understanding can be employed to critically assess states of affairs and to guide and prescribe action and reform. With this, moral cosmopolitanism has been established as the first core element of a cosmopolitan ethos, that can shape and guide how agents feel, think, talk and act about global issues. 